\title{
Failure Probability, Stress Distribution and Fracture Analysis of Experimental Screw for Micro Conical Abutment
}

\begin{abstract}
Antonio Braulino de Melo Filho ${ }^{1}{ }^{\circledR}$, João Paulo Mendes Tribst ${ }^{2}{ }^{\oplus}$, Nathália de

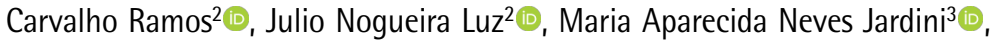
Alexandre Luiz Souto Borges ${ }^{2} \oplus$, Mauro Pedrine Santamaria ${ }^{3}{ }^{\oplus}$, Renata Marques de Melo² (-)
\end{abstract}

\begin{abstract}
The aim of this study was to evaluate the failure probability of two types of abutment screws after compressive load and to analyze the stress distribution with finite element method. Sixty (60) single-tooth implant restorations were assembled on titanium implants (e-fix, A.S. Technology - Titanium Fix). The groups were divided into Conventional screw (Screw neck $1.5 \emptyset \mathrm{mm}$ ) and Experimental screw (Screw neck constricted with $1.2 \varnothing \mathrm{mm}$ ). Specimens were subjected to single load to failure with compressive test according ISO 14801. The fractured specimens were subjected to stereomicroscopy for measurement of remaining screws inside the implant and characterization of fracture origin. Representative specimens were analyzed by scanning electronic microscopy. For finite element method (FEM), an identical 3D model of the two in vitro test groups were used with similar conditions $\left(30^{\circ}\right.$, $100 \mathrm{~N}$ load). The stress in the abutment screw was analyzed by von-Mises criteria. The results of strength means were $4132.5 \pm 76 \mathrm{MPa}$ and $4528.2 \pm 127.2$ for conventional and experimental groups, respectively. During microscopy, the mean $(\mathrm{mm})$ of the remaining screw piece inside the implants were $0.97 \pm 0.23$ and $1.32 \pm 0.12$ for conventional and experimental groups, respectively. In FEM, the conventional group showed stress concentered in an unfavorable region (peak of $39.23 \mathrm{MPa}$ ), while the experimental group showed more stress areas but less concentration than the conventional group (36.6 MPa). In using the tested experimental geometry, the abutment screw can have its strength improved, and the origin of failure can be more favorable to clinical resolution.
\end{abstract}

\author{
'Department of Social and \\ Pediatric Dentistry, UNESP - Univ \\ Estadual Paulista, Institute of \\ Science and Technology, São \\ José dos Campos, SP, Brazil \\ ${ }^{2}$ Department of Dental Materials \\ and Prosthodontics, UNESP - \\ Univ Estadual Paulista, Institute \\ of Science and Technology, São \\ José dos Campos, SP, Brazil \\ ${ }^{3}$ Department of Oral and Maxillofacial \\ Surgery and Periodontology, UNESP \\ - Univ Estadual Paulista, Institute \\ of Science and Technology, São \\ José dos Campos, SP, Brazil
}

Correspondence: João Paulo Mendes Tribst, Av. Eng. Francisco José Longo, 777, Jardim São Dimas, 12245-000 São José dos Campos, SP, Brazil. Tel: +55-12-98126-4653; 3947-9032. e-mail: joao.tribst@gmail.com

Key Words: finite element analyses, dental implant, abutment screw loosening, Weibull analysis

\section{Introduction}

The region most susceptible to fracture in an abutment screw is located at the junction between the threads and the neck (1). The geometry is abruptly altered in this region, and small equiaxial depressions visible by electron microscopy are formed during fracture of the material (1).

Another concern for the clinician is regarding maintenance of the torque during installation of the prosthetic components; since the screws of the abutment may also be subject to loosen under fatigue (2). This can be minimized, for example, by using thicker screws with an apical indexer (2).

Altering the geometry not only minimizes loosening, but also influences the load required for fracture, making the screws more resilient (3). The strength is directly connected to stress dissipated onto the body of the screw during masticatory load, and through finite element analysis method it is possible to observe that larger screws are less susceptible to reach critical fracture when compared with smaller diameter screws (4).

Although screw fracture is not the most recurring mechanical problem $(5,6)$, what makes abutment screw fractures so prominent in cases where they occur, is the difficulty in removing the apical remnant located inside the dental implant (7-9).

Since the fractured region usually is in the junction between the threads and the neck of the screw (1), the portion that remains inserted in the implant is responsible for maintaining torque at the time of the first thread $(8,10)$. Moreover, the ductile metal plastically deforms during the fracture which can modify the passivity between the implant and screw surfaces $(8,11)$ and impair the rotation of the parts. All these factors added to the limited access to the hole in the implant platform impair capturing the fractured screw and its removal.

Thus, if a fracture occurs, the screw geometry should provide a favorable portion for removal of the residue and not only increase the system's strength. In this respect, the creation of an industrial design of abutment screws containing a thinner portion could direct the fragility zone to a more external region, since it has already been shown that a smaller diameter of metal is less resistant in these situations (4).

In this way, the present study proposes to evaluate 
an experimental geometry for abutment screw regarding failure probability, stress distribution and failure mode. The hypotheses tested are that: 1 . The failure probability of the experimental geometry and the conventional geometry will be identical; 2 . the stress peak value will be similar, but the stressed region will be more favorable for the experimental geometry; and 3. the fracture origin will be more favorable for the experimental group.

\section{Material and Methods}

\section{Specimen Preparation}

The alveolus of each implant $(n=60)$ was milled with its long axis perpendicular to the horizontal plane in a polyurethane cylinder (F160, Axson Brasil, Socorro, SP). First, the base and catalyst from polyurethane resin were mixed in equal proportions and dispensed into a cylindrical silicone mold. After polymerization and perforation, external hexagon implants $(4 \times 13 \mathrm{~mm})$ were installed $(40 \mathrm{~N} / \mathrm{cm})$, leaving $3 \mathrm{~mm}$ outside the polyurethane resin.

Half of the implants $(n=30)$ received mini-abutments $(2.5 \times 4.0 \mathrm{~mm})$ installed $(20 \mathrm{~N} / \mathrm{cm})$ with their respective screws (e-fix, A.S. Technology - Titanium Fix, São José dos Campos, SP, Brazil). The other half received mini-abutments $(2.5 \times 4.0 \mathrm{~mm})$ installed $(20 \mathrm{~N} / \mathrm{cm})$ with experimental screws (e-fix, A.S. Technology - Titanium Fix, São José dos Campos, $\mathrm{SP}, \mathrm{Brazil)}$. This group was called experimental because the abutment screw had a $1.20 \mathrm{~mm}$ constriction in the smooth part of the neck in order to direct the fracture above the region of the threads (Fig. 1).

\section{Load to Failure}

This set was tested in a universal testing machine (DL1000, EMIC, São José dos Pinhais, Brazil). The load (crosshead speed of $0.5 \mathrm{~mm} / \mathrm{min}$ ) was applied in the top of crown with a $30^{\circ}$ angle (ISO 14801)

After fracturing the specimens, they were analyzed by stereomicroscopy (Discovery V20, CarlZeiss, Jena, Thuringia, Germany) and Scanning Electron Microscopy (Inspect S50, FEl Company, Brno, Czech Republic) for analyzing the fracture origins. The remnants inserted in the implant were measured according to their length.

The load for fracture $(\mathrm{N})$ was applied in the following

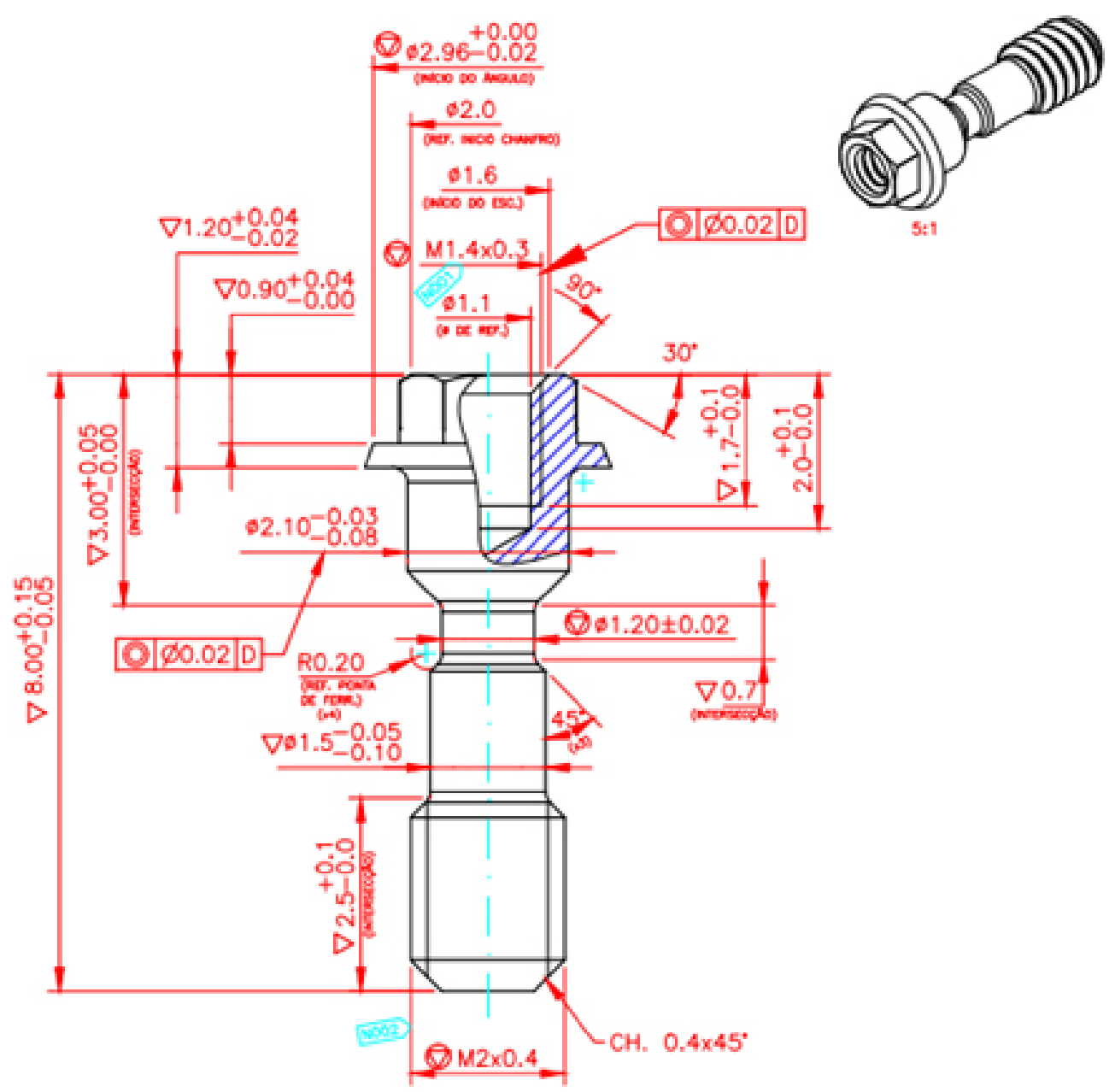

Figure 1. Industrial design of the experimental screw with $1.20 \mathrm{~mm}$ constriction. 
equations for calculating fracture strength (MPa):

$p=\left(3 E_{1} / 4 k r\right)^{\frac{2}{3}} L^{\frac{1}{3}} / \pi$

and

$$
k=\left(9 / 16\left\{\left[1-(v)^{2}\right]+\left[1-(v)^{2}\right]\right\}\right) E / E^{\prime}
$$

Where $L=\operatorname{load}, r=$ radius of the sphere, $v=$ Poisson ratio of flat tip, $v_{s}=$ Poisson ratio for sphere, $E=$ elastic modulus of flat tip and elastic modulus of sphere (12).

\section{Weibull Analysis}

The data in MPa were then submitted to Weibull analysis to determine the structural homogeneity of the set from the following equation:

$$
P_{f}=1-\exp \left[-\left(\frac{\sigma}{\sigma_{o}}\right)^{m}\right]
$$

The equation represents the function of the Weibull distribution with two parameters in which the failure probability (Pf) of an area or volume under stress can be estimated by two parameters, the Weibull modulus $(\mathrm{m})$ and the characteristic strength $\left(\sigma_{0}\right)$. A low modulus corresponds to a large variability in the strength data, and consequently a less reliable material. Characteristic strength refers to the strength value in which $63.2 \%$ of the specimens will fail (12).

Weibull analysis was done by ranking the values in

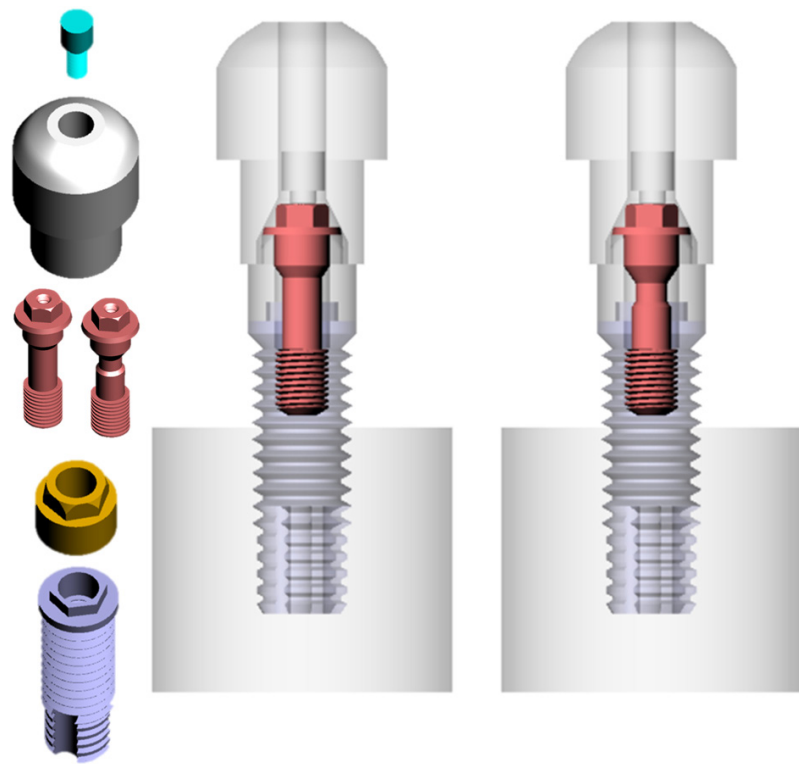

Figure 2. Three-dimensional model used in the finite element analysis of the structures. Two abutment screws are presented to illustrate the difference between the groups. ascending order and using the Weibull command by least squares method on Minitab Software 17.1.0 (Minitab Inc.).

\section{Finite Element Method}

A numerical simulation by finite elements was used to identify the stress distribution in the system. This is a tool capable of elucidating the mechanical behavior of implants (13).

The implant $(4 \times 13 \mathrm{~mm})$ and the prosthetic component $(2.5 \times 4 \mathrm{~mm})$ were designed with an external hexagon prosthetic connection using CAD software (Rhinoceros 4.0 - SR9 McNeil North America). A simplified prosthetic crown (ISO 14801:2007) was also designed and a prosthetic screw responsible for fixating the crown on the abutment was also simulated. After this step, the 3D model was duplicated according to the abutment screw: a model containing a screw with a $1.5 \mathrm{~mm}$ diameter neck and another with a screw of equal diameter, but containing a $1.2 \mathrm{~mm}$ constriction below the head (Fig. 2).

The geometries were subsequently exported to Ansys 17.2 software, and the elastic properties (14-16) of the materials (elastic modulus and Poisson ratio) were attributed according to literature (Table 1). A mesh was generated through quadratic tetrahedral elements, characterized by a triangular pyramidal base, totaling 74,016 elements joined by 128,557 nodes using friction contact $(\mu=0.3$ ). The mesh convergence test was performed with $10 \%$ of difference between the results.

For finite element analysis, a static mechanical analysis was performed within the elastic limit, in which all geometries were composed of homogeneous materials with linear and isotropic behavior. In the simulation, a load $(100 \mathrm{~N})$ was applied on the top of crown and a torque of $20 \mathrm{~N} / \mathrm{cm}$ was simulated for the screw.

\section{Results}

The fracture origin was always in the screw that connects the abutment to the implant above the first thread in control group. In the experimental group, the fracture was on the upper part of the screw, near to the constriction region. The amount of fractured screw remaining inside the implant was calculated by subtracting the full length by

Table 1. Distribution of mechanical properties of the materials used in Finite Element Analysis

\begin{tabular}{lcc}
\hline Material & Elastic modulus (GPa) & Poisson ratio \\
\hline Titanium & 110 & $0.33(14)$ \\
Ni-Cr & 206 & $0.31(5)$ \\
Polyurethane & 3.6 & $0.31(6)$ \\
\hline
\end{tabular}


measuring the coronary portion through optical microscopy (40x). Mean values and standard deviation of the lengths of the control group screws were $0.97 \mathrm{~mm} \pm 0.23 \mathrm{~mm}$, while they were $1.32 \mathrm{~mm} \pm 0.12 \mathrm{~mm}$ in the experimental group.

Mean fracture strength of the screw was respectively $4132.5 \pm 76 \mathrm{MPa}$ and $4528.2 \pm 127.2 \mathrm{MPa}$ for the control and experimental groups, respectively.

The strength of the experimental screw was statistically higher than the control screw according to the Tstudent test $(p<0.001)$. Weibull analysis showed that the control group had a higher modulus $(m)$, which means a lower dispersion

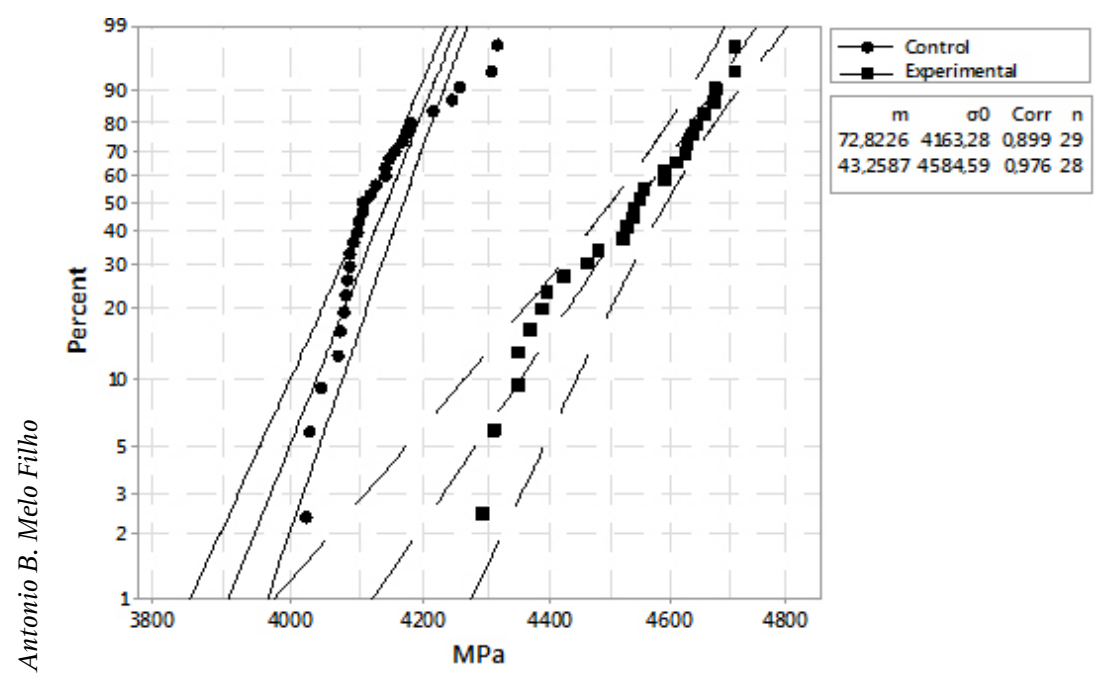

Figure 3. Weibull graph with failure probability (\%) of implants as a function of strength (MPa).

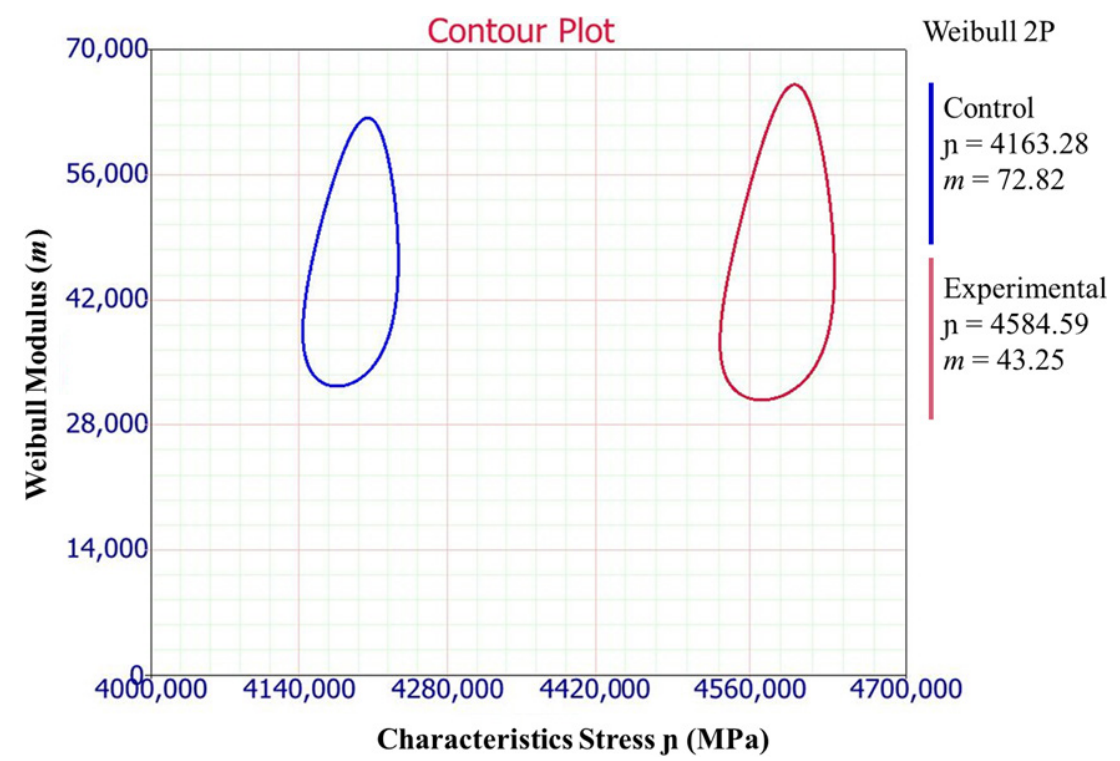

Figure 4. Contour plot showing " $m$ " as an indicator of structural reliability (Weibull modulus) vs. characteristic stress $(\eta)$. The non-overlap between groups indicates significant difference. of strength data (Figs. 3 and 4). The calculated $m$ and the characteristic strength $(\eta)$ are depicted in the contour plot (Fig. 4). The confidence interval for $m$ are 62.58 to 84.74 for control group and 31.92 to 58.61 for experimental group. Considering the $\eta$, the confidence interval range from 4139.83 to 4186.86 for control group and 4543.38 to 4626.18 for experimental screw. Therefore, there was a significant difference between them considering the absence of overlap of the contours (95\%).

SEM analyzes showed small depressions typical of ductile fractures in both groups. The fractures occurred as a cone cup, and the direction of crack propagation is shown below (Fig. 5).

The coherence of the model to FEM was verified within 10\% of the generated mesh convergence. The stress dissipated was proportional in both groups for simultaneous deformation of all bodies, presenting an absence of gaps in modeling.

According to von-Mises criterion for analyzing ductile solids, the screw of both groups was the body with the highest stress concentration, corroborating the type of failure generated in the in vitro experiment. The group containing an experimental screw showed morestress concentration zones in the screw neck region, suggesting that this screw would fail in different regions but with similar load than the control group (Fig. 6). It is possible to observe that the experimental group concentrates less stress than the conventional group, suggesting that the constriction would not completely inhibit the stress generated in the thread zone, but would decrease its magnitude (Fig. 6). This observation is important and corroborates the fracture results of the in vitro experiment.

\section{Discussion}

The present study evaluated an experimental geometry for abutment screws (Figs. 1 and 2), performing the failure probability, stress distribution and fracture origin characterizations. The first hypothesis was rejected, since the experimental group showed significantly higher strength than the 
control group (Fig. 3 and 4); the second hypothesis was accepted because the stress peaks of both geometries were between $30 \mathrm{MPa}$ and $40 \mathrm{MPa}$, but the concentration was modified by geometry (Figs. 5 and 6). Finally, the third hypothesis was accepted because the fracture origin location was more favorable in the experimental group.

Thus, our results demonstrate that a constriction of 0.3 $\mathrm{mm}$ in the diameter of the neck region can change the whole system behavior. These results are supported by findings in the literature which demonstrate that modified screw

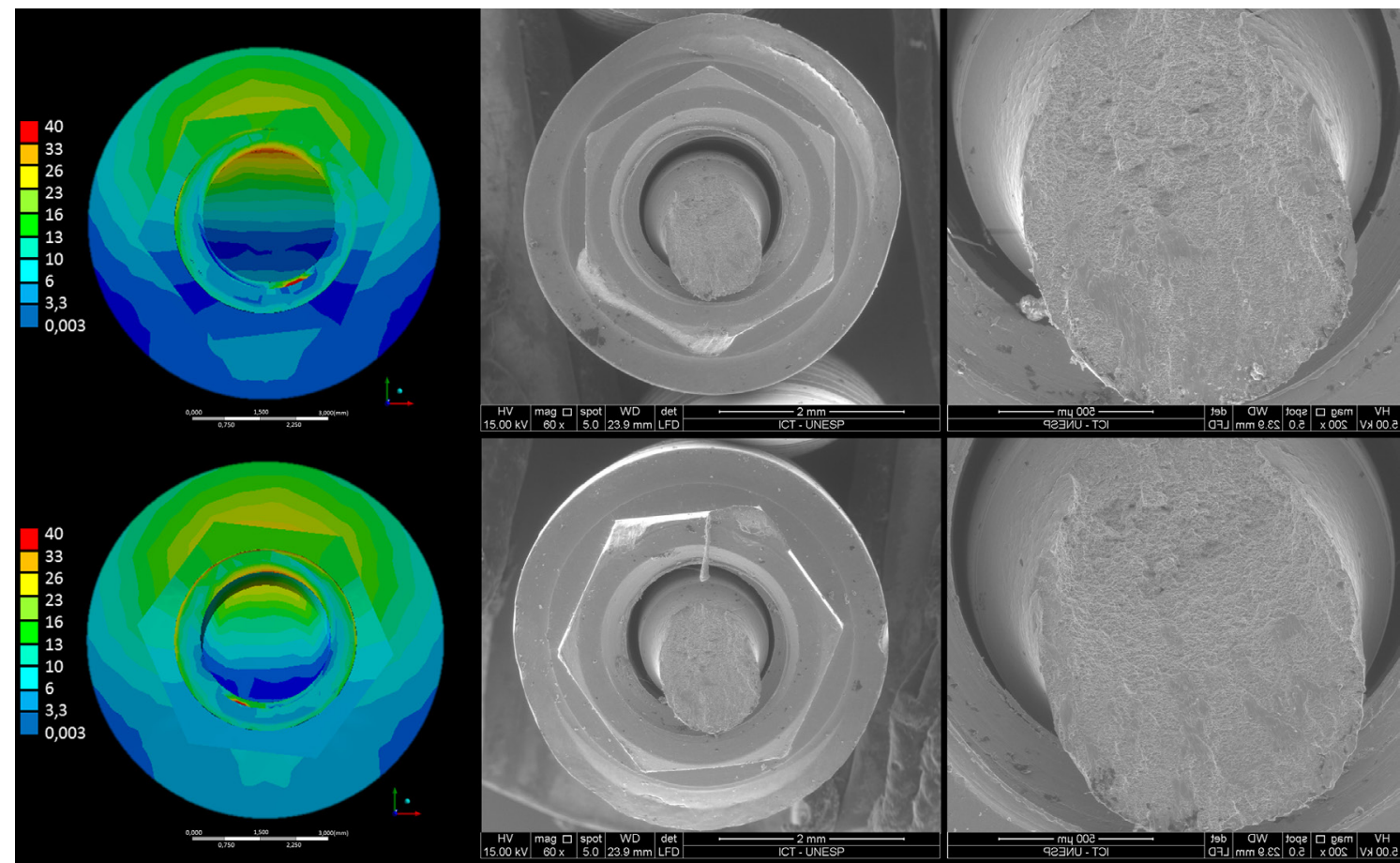

Figure 5. Simulation of abutment screw fracture and SEM of representative specimen after in vitro fracture. The first line shows the conventional group with higher stress near the threads and worse fracturing; the second line shows the experimental group with a decrease of stress in the thread region and corroborating test.

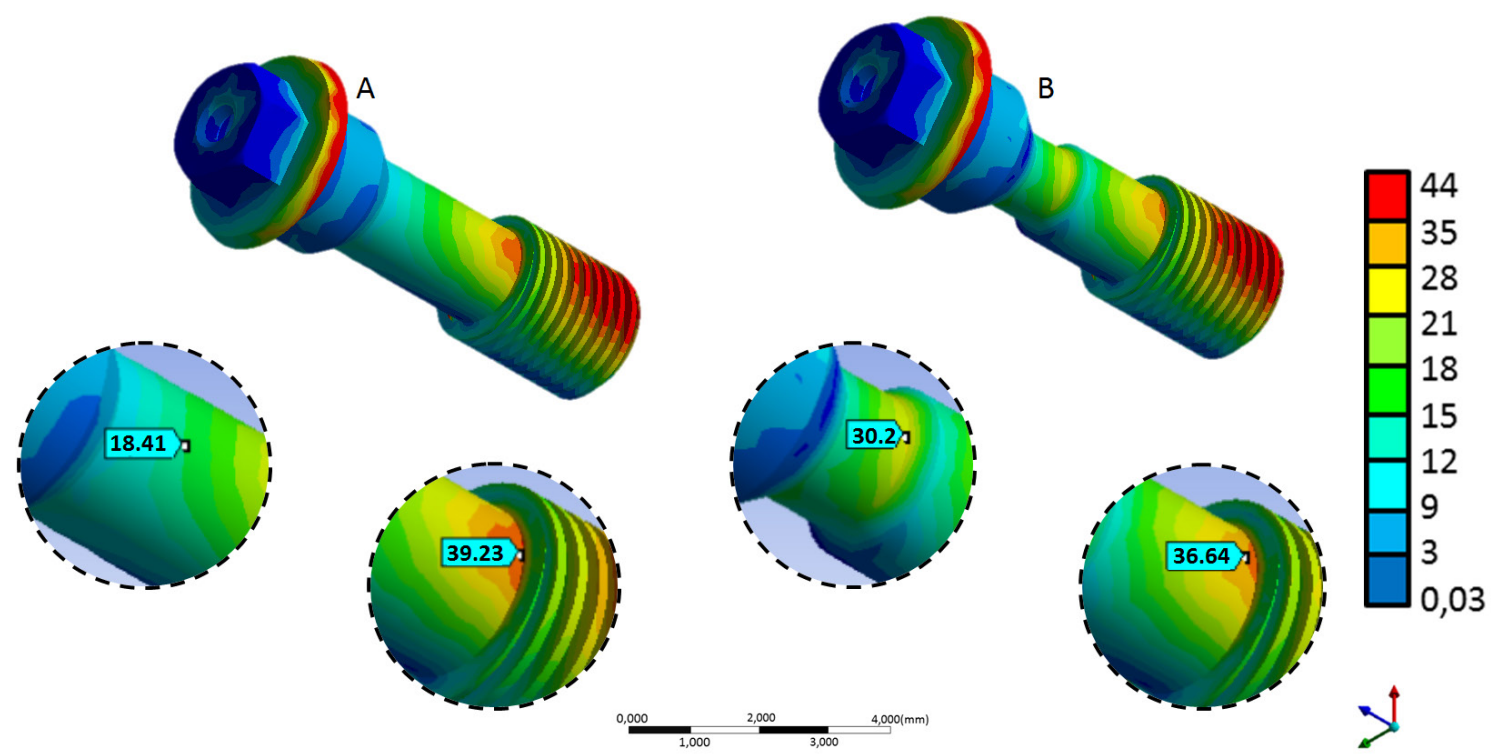

Figure 6. Von-Mises stress of the abutment screws after static mechanical test; the control group is on the left and the experimental group is on the right. The figures within circles are increases of screw sites with the present quantitative stress values. 
geometry tends to also change fracture strength results $(1,2)$ and stress distribution of the set $(4,17)$.

During loading of specimens on the test machine, the control group always exhibited its fracture region located on the first screw thread of the abutment, which is in agreement with previous studies $(1,2,4,7-9)$. However, the fracture did not occur $100 \%$ in the constriction region in the experimental group, but a greater amount of the screw remainder was inserted inside the implant, which would facilitate its capture by tweezers during removal.

The removal of the apical portion of the fractured screw from within the implant is widely reported in the literature through techniques that aim at maintaining the internal threads of the implant $(8,10,11,18-20)$, although this is not always possible (9).

These techniques mostly require specific instruments and professional skills, in addition to clinical time directed to that end (18).The idea of a screw allowing favorable fracture means a better prognosis, even if the strength is reduced. However, the results of this study are unique, as not only the fracture origin location was more favorable, but also the abutment screw fracture strength improved in the experimental group (Figs. 3 and 4).

These results were complemented by finite element analysis, which shows that the constriction exerts the function of concentrating part of the stress, thereby decreasing the peak at the beginning of the threads (Figs. 5 and 6). Within a maximum 10\% difference between the results (based in mesh convergence test), it is possible to observe that there is significant difference between the groups for screw head in Figure 6 . As the tested prosthetic components are screws with high machined precision, it is unlikely that there are large structural defects on the surface (21). This means that if an object presents distributed stress throughout its surface, as in the experimental group, the mechanical behavior may be higher than an object that presents a single region of critical stress (22).Basically, the constriction of the experimental screw acts as a damping system, preventing the beginning of the threads from being the only fragile region (Fig. 6).

The theory that the experimental screw is mechanically better because it allows a larger area of stress is also based on the smaller modulus $(\mathrm{m})$ found during the Weibull test. As already described, this is because that constriction does not guarantee only a single stress concentration region, making it so that several failure profiles appeared during the fracture of the screws, and thus strength data dispersion was greater. In contrast, the control group showed an evident failure in a single region and stress concentration in the same location, which justifies that this screw will similarly fail in almost all the test specimens; thus, the data will be less dispersed. It is worth mentioning that despite greater data dispersion from the experimental group, it is suggested that predictability with the use of this screw is less precise, and all strength values were higher than the strength values of the control group (Fig. 3 and 4).

The literature demonstrates that abutment screw fracture can be minimized if the screw diameter is increased $(3,23)$, but the diameter of the implant needs to be altered at the expense of the axial walls, thus making them thinner or increasing the total diameter and preventing less bone regions available (23). In addition, these works seek to improve strength, but not to promote a change in the origin of the fracture to a favorable situation of being clinically treated. Therefore, our results can be suggested as promising so that only the screw is mechanically modified and the system is improved.

Modifying part of a screw's neck diameter has already been reported in the literature as an alternative, so when a catastrophic failure occurs the treatment would be reversible (24). The difference in question is that the work evaluated a transpedicular screw for treating movement disorders of spine vertebrae. These implants are similar to those used in dentistry mainly because they are composed of titanium alloys. Similarly to our results, the authors found a fracture origin region similar to the region identified through finite element analysis, and also found that a geometry alteration could be favorable for the fracture to occur farther from the threads. The main difference was that the forces exerted on the transpedicular screw exerted perfect flexion perpendicular to the implant, whereas the loading in the present study included oblique forces according to ISO 14801. This difference in load application is reflected in the strength result, since the present study alleviated the stress peaks of the experimental screw rather than simply favoring the fracture in the most promising region.

It is notable that all in vitro work has limitations, since the oral environment has variations in temperature, $\mathrm{pH}$ and masticatory force loads (25). Making it an impossible environment to reproduce in laboratory conditions. In addition, the mechanical test was performed with simplified prosthetic crown geometry $(13,22)$ with an extreme inclination and exposed threads, which is a situation due to the necessary standardizations. Another point of discussion is that computational simulation, although not linear, uses homogeneous materials with an absence of internal defects, which is not clinically common. In order for the screws tested here to be in fact indicated for wide clinical use, it is still necessary to evaluate the effect of cyclic fatigue on the longevity and even on the torque maintenance of these prosthetic pieces.

Thus, in spite of the limitations of this study, it is possible to conclude that the abutment screw can have its strength 
improved and the failure origin is more favorable when a constriction is made just below the screw head.

\section{Resumo}

0 objetivo deste estudo foi avaliar a probabilidade de falha de dois tipos de parafusos para pilar protético após a compressão e analisar a distribuição da tensão com o método dos elementos finitos. Sessenta (60) restaurações unitárias foram montadas em implantes de titânio (e-fix, A.S. Technology - Titanium Fix). Os grupos foram divididos em parafusos convencionais (parafuso de pescoço $1,5 \emptyset \mathrm{mm}$ ) e parafuso experimental (parafuso de pescoço estreitado com 1,2ø $\mathrm{mm}$ ). As amostras foram sujeitas ao teste de compressão de acordo com ISO 14801. Os espécimes fraturados foram submetidos a estereomicroscopia para a mensuração dos parafusos restantes dentro do implante e caracterização da origem da fratura. Os espécimes representativos foram analisados por microscopia eletrônica de varredura. Para o método de elementos finitos (FEM), utilizou-se um modelo 3D idêntico dos dois grupos de teste in vitro com condições semelhantes $\left(30^{\circ}, 100 \mathrm{~N}\right)$. A tensão no parafuso do pilar foi analisada pelo critério de von-Mises. Os resultados de resistência a compressão foram $4132,5 \pm 76 \mathrm{MPa}$ e $4528,2 \pm 127,2$ para grupos convencionais e experimentais, respectivamente. Durante a microscopia, a média do remanescente do parafuso restante dentro dos implantes foi de $0,97 \pm 0,23$ e 1,32 $\pm 0,12 \mathrm{~mm}$ para os grupos convencionais e experimentais, respectivamente. Em FEM, o grupo convencional mostrou tensão concentrada em uma região desfavorável (pico de 39,23 MPa), enquanto o grupo experimental apresentou mais áreas de tensão, porém menor concentração do que o grupo convencional (36,6 MPa). Ao usar a geometria experimental testada, o parafuso do pilar pode ter sua resistência melhorada e a origem da falha pode ser mais favorável à resolução clínica.

\section{Acknowledgements}

The authors acknowledge the Research Foundation of the State of São Paulo (FAPESP - Grant 13/17733-0)

\section{References}

1. Khraisat $A$, Stegaroiu $R$, Nomura $S$, Miyakawa 0 . Fatigue resistance of two implant/abutment joint designs. J Prosthet Dent 2002;88:604-10.

2. Piermatti J, Yousef $H$, Luke $A$, Mahevich $R$, Weiner $S$. An in vitro analysis of implant screw torque loss with external hex and internal connection implant systems. Implant Dent 2006;15:427-35.

3. Jabbari YSA, Fournelle R, Ziebert G, Toth J, Lacopino AM. Mechanical behavior and failure analysis of prosthetic retaining screws after longterm use in vivo. Part 4: failure analysis of 10 fractured retaining screws retrieved from three patients. J Prosthodont 2008;17:168-80.

4. Peixoto HE, Bordin D, Del Bel Cury AA, da Silva WJ, Faot F. The role of prosthetic abutment material on the stress distribution in a maxillary single implant-supported fixed prosthesis. Mater Sci Eng C Mater Biol Appl 2016;65:90-6.

5. Jamt T: Failure and complications in 391 consecutively inserted fixed prostheses supported by Branamark implants in edentulous jaws. A study of treatment from the time of prosthesis placement to the first annual checkup. Int J Oral Maxillofac Implants 1991;6:270-6.

6. Eckert SE, Wollan PC. Retrospective review of 1170 endosseous implants placed in partially edentulous jaws. J Prosthet Dent 1998;79:415-21.

7. Nergiz I, Schmage $P$, Shahin R. Removal of a fractured implant abutment screw: a clinical report. J Prosthet Dent 2004 91, 513-517.
8. Satwalekar $P$, Chander KS, Reddy BA, Sandeep N, Sandeep $N_{\text {, }}$ Satwalekar T. A Simple and Cost Effective Method used for Removal of a Fractured Implant Abutment Screw: A Case Report. J Int Oral Health 2013; 5: 120-123.

9. Shah K, Lee DJ. An alternative approach for the management of fractured implant abutment screws on a mandibular implant-retained overdenture: A clinical report. J Prosthet Dent 2016;115:402-5.

10. Yilmaz B, McGlumphy E. A technique to retrieve fractured implant screws. J Prosthet Dent 2011;105:137-8.

11. Santos MDB, Pfeifer AB, Silva MRP, Sendyk CL, Sendyk WiR. Fracture of abutment screw supporting a cemented implant-retained prosthesis with external hexagon connection: a case report with SEM Evaluation. Journal of Applied Oral Science. 2007;15:148-151.

12. Nelson WB. Accelerated Testing. New York: John Wiley \& Sons, Inc; 1990.

13. Tribst JPM, Dal Piva AMO, Borges ALS. Biomechanical tools to study dental implants: A literature review. Braz Dent Sci 2016;19:5-11.

14. Benzing UR, Gall H, Weber H. Biomechanical aspects of two different implant-prosthetic concepts for edentulous maxillae. Int J Oral Maxillofac Implants 1995;10:188-98.

15. Stegaroiu R, Sato T, Kusakari H, Miyakawa 0. Influence of restoration type on stress distribution in bone around implants: A threedimensional finite element analysis. Int J Oral Maxillofac Implants 1998;13:82-90.

16. Myashiro $M$, Suedan $V$, Moretti Neto, RT, Ferreira PM, Rubo JH. Validation of an experimental polyurethane model for biomechanical studies on implant supported prosthesis - tension tests. J Appl Oral Sci 2011;19:244-8

17. Alkan I, Sertgöz A, Ekici B. Influence of occlusal forces on stress distribution in preloaded dental implant screws. J Prosthet Dent 2004;91:319-25.

18. Assaf M, Gharbyeh AZA. Screw-retained crown restorations of single implants: A step-by-step clinical guide. Eur J Dent 2014;8:563-570.

19. Krishnan V, Tony Thomas C, Sabu I. Management of abutment screw loosening: review of literature and report of a case. J Indian Prosthodont Soc 2014;14:208-214.

20. Flanagan, D. Management of a fractured implant abutment screw. J Oral Implantol 2016:42:508-511.

21. Revankar GD, Shetty R, Shrikantha SR, Gaitonde VN. Analysis of surface roughness and hardness in titanium alloy machining with polycrystalline diamond tool under different lubricating modes. Mater Res 2014;17:1010-1022.

22. Wu, W., D. Gastaldi, K. Yang, L. L. Tan, L. Petrini, and F. Migliavacca. Finite element analyses for design evaluation of biodegradable magnesium alloy stents in arterial vessels. Mater Sci Eng B 2011;176:1733-1740.

23. Mao Z, Yi D, Cao G. Influence of sizes of abutments and fixation screws on dental implant system: a non-linear finite element analysis. Biomed Tech 2017 28;62:357-364.

24. Chao CK, Hsu CC, Wang JL, Lin J. Increasing bending strength and pullout strength in conical pedicle screws: biomechanical tests and finite element analyses. J Spinal Disord Tech 2008;21:130-138.

25. Faran Ali SM, Tanwir F. Oral microbial habitat a dynamic entity. J Oral Biol Craniofac Rese 2012;2:181-187.
Received July 8, 2018

Accepted August 16, 2018 